\title{
ECLETICA
}

www.scielo.br/eq

Volume 30, número 3, 2005

\section{Synthesis, characterization and thermal studies on solid 3-methoxybenzoate of some bivalent transition metal ions}

\author{
A. C. Vallejo, A. B. Siqueira, E. C. Rodrigues, E.Y. Ionashiro, G. Bannach, M. Ionashirol \\ Instituto de Química, UNESP, C. P. 355, CEP 14801 - 970, Araraquara, SP, Brazil. \\ ${ }^{2}$ Corresponding author: massaoi@iq.unesp.br
}

\begin{abstract}
Solid-state M-3-MeO-Bz compounds, where M stands for bivalent $\mathrm{Mn}, \mathrm{Co}, \mathrm{Ni}, \mathrm{Cu}$ and $\mathrm{Zn}$ and 3-MeO-Bz is 3-methoxybenzoate, have been synthesized. Simultaneous thermogravimetry and differential thermal analysis (TG-DTA), differential scanning calorimetry (DSC), X-ray powder diffractometry, infrared spectroscopy, and chemical analysis were used to characterize and to study the thermal behaviour of these compounds. The results led to information about the composition, dehydration, thermal stability and thermal decomposition of the isolated compounds.
\end{abstract}

Keywords: bivalent transition metals; 3-methoxybenzoate; thermal behaviour.

\section{Introduction}

Several metal-ion salts of benzoic acid, as well as some benzoic acid derivatives, have been investigated in aqueous solutions and in solid state.

In aqueous solutions, Yun and co-workers [1] reported the thermodynamics of complexation of lanthanides by some benzoic acid derivatives. Wang and co-workers [2] reported the spectroscopic study of trivalent lanthanides with several carboxylic acids, including benzoic acid. Arnaud and Georges [3] described the influence of $\mathrm{pH}$, surfactant and synergic agent on the luminescent properties of terbium chelates with benzoic acid derivatives. Choppin and co-workers [4] reported the thermodynamic of complexation of lanthanides by benzoic and isophthalic acids. Lam and co-workers [5] described the synthesis, crystal structure and photophysical and magnetic properties of dimeric and polymeric lanthanide complexes with benzoic acid and its derivatives.

In the solid state, Wendlandt synthesized and reported the thermal stability and thermal decomposition of thorium salts with several organic acids, including 4-methoxybenzoic acid [6], as well as benzoic and m-hydroxybenzoic acids [7].
Glowiack and co-workers [8] reported the reaction of bivalent copper, cobalt and nickel with 3-hidroxy-4-methoxy and 3-methoxy-4hidroxybenzoic acids and a structure for these compounds has been proposed on the basis of spectroscopic and thermogravimetric data. Brzyska and Karasinski [9] described the thermal decomposition of thorium salts of benzoic and 4methoxybenzoic acids in air atmosphere. Ferenc and Walkow-Dziewulska [10] reported the synthesis and characterization of 2,3-dimethoxybenzoates of heavy lanthanides and yttrium by elemental analysis, IR spectroscopy, thermogravimetric studies and Xray diffraction measurements.

In the present paper, solid-state compounds of $\mathrm{Mn}$ (II), Co (II), $\mathrm{Ni}$ (II), Cu (II) and Zn (II) with 3-methoxybenzoate were prepared.

The compounds were investigated by means of chemical analysis, X-ray powder diffractometry, infrared spectroscopy, differential scanning calorimetry (DSC) and simultaneous thermogravimetry-differential thermal analysis (TGDTA). The results allowed us to acquire information concerning these compounds in the solid state, including their thermal stability and thermal decomposition. 


\section{Experimental}

The 3-methoxybenzoic acid, 3- $\mathrm{CH}_{3} \mathrm{O}-\mathrm{C}_{6} \mathrm{H}_{4}-$ $\mathrm{CO}_{2} \mathrm{H}(3-\mathrm{MeO}-\mathrm{HBz}) 98 \%$ was obtained from Acros organics and purified by recrystallization. Thus, aqueous suspension of $3-\mathrm{MeO}-\mathrm{HBz}$ was heated near ebullition until total dissolution and cooled to ambient temperature. The crystal in needle form was isolated and after dry kept in a plastic flask. The hydrated basic carbonates of Mn (II), Co (II), $\mathrm{Ni}$ (II), $\mathrm{Cu}$ (II) and $\mathrm{Zn}$ (II) were prepared by adding slowly with continuous stirring satured sodium carbonate solution to the corresponding metal chloride solutions or sulphate for copper until total precipitation of the metal ions. The precipitates were washed with distilled water until elimination of chloride or sulphate ions (qualitative tests with $\mathrm{AgNO}_{3} / \mathrm{HNO}_{3}$ solution for chloride ions or $\mathrm{BaCl}_{2}$ solution for sulphate ions) and maintained in an aqueous suspension.

Solid state Mn (II), Co (II), Ni (II), Cu (II) and Zn (II) compounds were prepared by mixing the corresponding metal basic carbonates with 3methoxybenzoic acid, in slight excess. The aqueous suspension was heated slowly up to near ebullition, until total neutralization of the respective basic carbonates. The resulting solutions, except the copper compound, after cooled were maintained in an ice bath to recrystallize the acid in excess and filtered through a Whatman $\mathrm{n}^{\circ} 40$ filter paper. Thus, the aqueous solutions of the respective metal-3methoxybenzoates were evaporated in a water bath until near dryness and kept in a desiccator over anhydrous calcium chloride. The copper compound, after the neutralization the precipitate was washed with distilled water heated up to near ebullition, filtered through and dried on Whatman $\mathrm{n}^{\circ} 40$ filter paper, and also kept in desiccator. All attempts to synthesize the iron (II) compound were unsuccessful, due to the oxidation reaction of $\mathrm{Fe}$ (II) to Fe (III) during the drying of the compound, even by using nitrogen atmosphere.

In the solid-state compounds, metal ions, water and 3-methoxybenzoate contents were determined from TG curves. The metal ions were also determined by complexometry with standard EDTA solution [11, 12] after igniting the compounds of the respective oxides and their dissolution in hydrochloric acid solution.

$\mathrm{X}$-ray powder patterns were obtained with a SIEMENS D-5000 X-ray diffractometer using $\mathrm{Cu}$ $\mathrm{K} \alpha$ radiation $(\lambda=1.544 \AA$ ) and setting of $40 \mathrm{kV}$ and $20 \mathrm{~mA}$.

Infrared spectra for 3-methoxybenzoic acid, sodium 3-methoxybenzoate as well as for its metalion compounds were run on a Nicolet model Impact 400 FT-IR instrument, within the $4000-400 \mathrm{~cm}^{-1}$ range. The solid samples were pressed into $\mathrm{KBr}$ pallets.

Simultaneous TG-DTA curves were obtained with thermal analysis systems model SDT 2960, from TA instruments. The purge gas was an air flow of $150 \mathrm{~mL} \mathrm{~min}^{-1}$. A heating rate of $20^{\circ} \mathrm{C} \mathrm{min}^{-}$ ${ }^{1}$ was adopted with samples weighing about $7 \mathrm{mg}$. Alumina crucible was used for TG-DTA.

The DSC curves were obtained using a Mettler TA-4000 thermal analysis system. The purge gas was flowing air with a flow rate of $150 \mathrm{~mL} \mathrm{~min}^{-1}$. The heating rate was $20^{\circ} \mathrm{C} \mathrm{min}-1$ and the initial sample mass was about $7 \mathrm{mg}$. Aluminium crucible with perforated cover was used for DSC experiment.

\section{Results and Discussion}

The X-ray powder diffraction patterns, Fig. 1 show that the synthesized compound have a crystalline structure, without evidence for formation of an isomorphous series, except for the nickel compound that was obtained in amorphous state.

Infrared spectroscopic data on 3methoxybenzoic acid, 3-methoxybenzoate and its compounds with the metal ions considered in this work are shown in table 2 . The investigation was focused mainly within the $1700-1400 \mathrm{~cm}^{-1}$ range because this region is potentially most informative to assign coordination sites. In sodium 3methoxybenzoate, strong band at $1568 \mathrm{~cm}^{-1}$ and a medium intensity band located at $1402 \mathrm{~cm}^{-1}$ are attributed to the anti-symmetrical and symmetrical frequencies of the carboxylate groups, respectively $[13,14]$. The manganese, cobalt, nickel, copper and zinc compounds, presented practically the same symmetrical and anti-symmetrical vibrations of the $\mathrm{COO}^{-}$groups, when compared with the sodium salt, suggesting that the compounds have ionic character. In all the compounds, except for the copper one, the medium intensity band observed within 1682-1693 $\mathrm{cm}^{1}$ range are attributed to $\mathrm{C}=\mathrm{O}$ stretch of dimmer structure of the acid, suggest the presence of 3- 
methoxybenzoic acid in these compounds.

Simultaneous TG-DTA curves of the compounds are shown in Fig. 2. These curves show mass losses in consecutive and/or overlapping steps with partial losses which are characteristic for each compound. Only the copper compound shows an endothermic peak corresponding to the first mass loss ascribed to dehydration. For the other compounds, no endothermic peak compatible with the first mass loss due to the dehydration is observed. Based on the information of infrared spectra and DTA curves, samples of these compounds were heated in a long test glass tube up to the temperature corresponding to the first mass loss and under approximately the same conditions as the TG-DTA curves. In these experiments, sublimation for the nickel compound and sublimation followed by fusion and evaporation for manganese, cobalt and zinc compounds were observed.The sublimated materials were identified as 3-methoxybenzoic acid, by infrared spectra and m.p. $=106-108^{\circ} \mathrm{C}$ literature $; 105-108^{\circ} \mathrm{C}$, observed. The presence of $3-\mathrm{MeO}-\mathrm{HBz}$ in these compounds must be due to the aggregation phenomenon, indicating that the procedure used to eliminate the acid in excess is not efficient and that the acid is more soluble in 3-methoxybenzoate solution and it no recrystallize even an ice bath. Therefore the first mass loss up to $280^{\circ} \mathrm{C}(\mathrm{Mn})$, $200^{\circ} \mathrm{C}(\mathrm{Co})$ and $230^{\circ} \mathrm{C}(\mathrm{Ni}, \mathrm{Zn})$, is due to elimination of 3-methoxybenzoic acid.

Thus, Table 2 presents the analytical and thermoanalytical (TG) results for the prepared compounds, from which the general formula $\mathrm{Cu}(\mathrm{L})_{2} \cdot \mathrm{H}_{2} \mathrm{O}$ or $\mathrm{M}(\mathrm{L})_{2} \times \mathrm{xHL}$ can be established, where $\mathrm{M}$ represents $\mathrm{Mn}, \mathrm{Co}, \mathrm{Ni}$ and $\mathrm{Zn}, \mathrm{L}=3$ methoxybenzoate, $\mathrm{HL}=3$-methoxybenzoic acid and $\mathrm{x}=0.19(\mathrm{Mn}), 0.28(\mathrm{Co}), 0.13(\mathrm{Ni})$ and $0.081(\mathrm{Zn})$.

Manganese compounds. The TG-DTA and DSC curves are shown in Fig.2a. These curves show mass losses in two steps between $50-180^{\circ} \mathrm{C}$ and $180-500^{\circ} \mathrm{C}$ (TG), and endothermic peaks at $180^{\circ} \mathrm{C}$ (DTA, DSC), $100^{\circ} \mathrm{C}$ (DSC) and exothermic peaks at $360^{\circ} \mathrm{C}, 430^{\circ} \mathrm{C}$ (DTA, DSC), $474^{\circ} \mathrm{C}$ (DTA), $500^{\circ} \mathrm{C}$ and $520^{\circ} \mathrm{C}$. The first mass loss that occurs through a slow process is attributed to the loss of $0.19 \mathrm{HL}$ (3methoxybenzoic acid) $($ calcd. $=7.49 \% ; \mathrm{TG}=$ $7.46 \%$ ). The second step that occurs through a fast process is ascribed to the thermal decomposition of the compounds that occurs in a single step (Calcd.
$=72,76 \% ; \mathrm{TG}=72.92 \%$ ), with formation of $\mathrm{Mn}_{3} \mathrm{O}_{4}$, as final residue (Calcd. 19.75\%; TG $=19.57 \%$ ), and confirmed by X-ray powder diffractometry. The endothermic peaks at $100^{\circ} \mathrm{C}$ (DSC and $180^{\circ} \mathrm{C}$ (DTA, DSC), are due to sublimation of 3-MeO-BP and fusion of the compounds, respectively, and in agreement with the experiment already described, with sample heated in a long test tube. The exothermic peaks at $360^{\circ} \mathrm{C}, 430^{\circ}$ and $475^{\circ} \mathrm{C}$ (DTA, DSC), 500 and $520^{\circ} \mathrm{C}$ (DSC) are attributed to the oxidation of the organic matter.

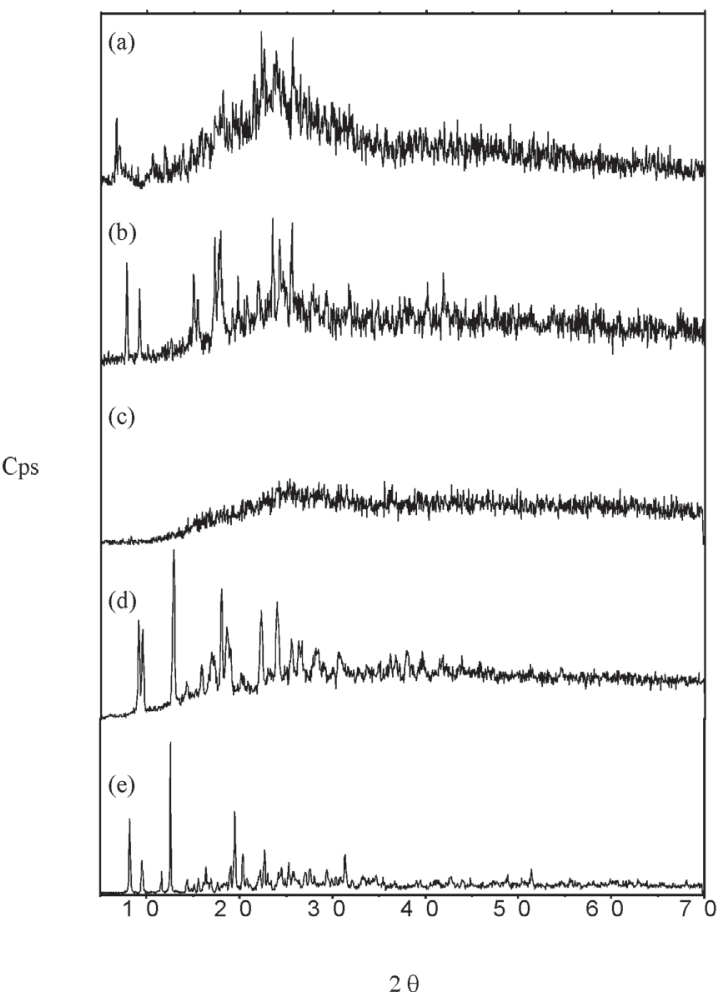

Figure 1. X-ray powder diffraction patterns of the compounds: (a) $\mathrm{Mn}(\mathrm{L})_{2} .0 .19 \mathrm{HL}$, (b) $\mathrm{Co}(\mathrm{L})_{2} 0.28 \mathrm{HL}$, (c) $\mathrm{Ni}(\mathrm{L})_{2} .0 .13 \mathrm{HL}$, (d) $\mathrm{Cu}(\mathrm{L})_{2} \cdot \mathrm{H}_{2} \mathrm{O}$ and (e) $\mathrm{Zn}(\mathrm{L})_{2} \cdot 0.081 \mathrm{HL} \quad(\mathrm{L}=4-$ methoxybenzoate, $\mathrm{HL}=4$-methoxybenzoic acid).

Cobalt compound. The TG-DTA and DSC curves are shown in Fig. 2b. These curves show mass losses in four consecutives and/or overlapping steps between $80-200^{\circ} \mathrm{C}, 200-380^{\circ} \mathrm{C}, 380-480^{\circ} \mathrm{C}$ and $900-920^{\circ} \mathrm{C}(\mathrm{TG})$ and endothermic peaks at $235^{\circ} \mathrm{C}(\mathrm{DTA}, \mathrm{DSC})$ and $900^{\circ} \mathrm{C}$ (DTA), and exothermic peaks at $480^{\circ} \mathrm{C}$ (DTA, DSC) and $490^{\circ} \mathrm{C}$ (DSC). The first mass loss, without thermal event observed in the DTA and DSC curves is ascribed to the loss of 
0.28 HL (3-methoxybenzoic acid) (Calcd. = $10.55 \%$; $\mathrm{TG}=10.61 \%)$. The endothermic peak at $235^{\circ} \mathrm{C}\left(235^{\circ} \mathrm{C}\right) \mathrm{DTA}, \mathrm{DSC}$ is attributed to the fusion of the compound. The second and third steps with losses of $26.13 \%$ and $43.77 \%$, corresponding to the single exothermic peak (DTA) or a broad exothermic between $410-550^{\circ} \mathrm{C}$ (DSC), are attributed to the thermal decomposition of the compound. The profiles of the TG-DTA curves show that the oxidation of the organic matter occurs with combustion. The total mass loss up to $480^{\circ} \mathrm{Cis}$ in agreement with the formation of $\mathrm{Co}_{3} \mathrm{O}_{4}$ (Calcd. $=80.13 \%$; $\mathrm{TG}=80.51 \%)$. The last step corresponding to the small endothermic peak is due to the reduction of $\mathrm{Co}_{3} \mathrm{O}_{4}$ to $\mathrm{CoO}$ (Calcd. $=1.32 \%$; $\mathrm{TG}=1.21 \%$ ) and is in agreement with literature. $[15,16]$. X-ray powder patterns of the residue obtained at $1000^{\circ} \mathrm{C}$ is coincident with that obtained for $\mathrm{Co}_{3} \mathrm{O}_{4}$; this is due to the reoxidation reaction of $\mathrm{CoO}$ to $\mathrm{Co}_{3} \mathrm{O}_{4}$ which occurs on cooling the former in an air atmosphere at room temperature [16].

Table 1. Spectroscopic data for 3-methoxybenzoic acid (HL), sodium 3-methoxybenzoate (NaL), and compounds with some bivalent metal ions ${ }^{\mathrm{a}}$.

\begin{tabular}{|c|c|c|c|c|}
\hline Compound & $\begin{array}{c}\mathrm{V}_{(\mathrm{O}-\mathrm{H})} \mathrm{H}_{2} \mathrm{O}^{\mathrm{b}} \\
\left(\mathrm{cm}^{-1}\right)\end{array}$ & $\begin{array}{c}\mathrm{V}_{\mathrm{as}\left(\mathrm{COO}^{-}\right)^{\mathrm{c}}} \\
\left(\mathrm{cm}^{-1}\right)\end{array}$ & $\begin{array}{c}\mathrm{v}_{\mathrm{sym}\left(\mathrm{COO}^{-}\right)^{\mathrm{c}}} \\
\left(\mathrm{cm}^{-1}\right)\end{array}$ & $\begin{array}{l}v_{\left(\mathrm{C}=\mathrm{O}^{-}\right)^{\mathrm{d}}} \\
\left(\mathrm{cm}^{-1}\right)\end{array}$ \\
\hline HL & - & - & - & 1690 \\
\hline $\mathrm{NaL} . \mathrm{H}_{2} \mathrm{O}$ & $3450_{\mathrm{br}}$ & $1568_{\mathrm{s}}$ & $1402_{\mathrm{s}}$ & - \\
\hline $\mathrm{Mn}(\mathrm{L})_{2} \cdot 0.19 \mathrm{HL}$ & - & $1556_{\mathrm{s}}$ & $1404_{s}$ & $1682_{\mathrm{m}}$ \\
\hline $\mathrm{Co}(\mathrm{L})_{2} \cdot 0.28 \mathrm{HL}$ & - & $1529_{\mathrm{s}}$ & $1385_{\mathrm{s}}$ & $1691_{\mathrm{m}}$ \\
\hline $\mathrm{Ni}(\mathrm{L})_{2} \cdot 0.13 \mathrm{HL}$ & - & $1570_{\mathrm{s}}$ & $1395_{\mathrm{m}}$ & $1692_{\mathrm{m}}$ \\
\hline $\mathrm{Cu}(\mathrm{L})_{2} \cdot \mathrm{H}_{2} \mathrm{O}$ & $3464_{\mathrm{br}}$ & $1595_{\mathrm{s}}$ & $1418_{s}$ & - \\
\hline $\mathrm{Zn}(\mathrm{L})_{2} \cdot 0.081 \mathrm{HL}$ & - & $1581 \mathrm{~s}$ & $1404_{\mathrm{s}}$ & $1693_{\mathrm{m}}$ \\
\hline
\end{tabular}

a br: broad, $\mathrm{m}=$ medium, $\mathrm{s}=$ strong.

${ }^{\mathrm{b}} \mathrm{V}_{(\mathrm{o}-\mathrm{H})}$ : hydroxyl group stretching frequency.

${ }^{\mathrm{c}} \mathrm{v}_{\left.\text {sym( } \mathrm{COO}^{-}\right)}$and $\mathrm{v}_{\left.\text {as( } \mathrm{COO}^{-}\right)}$: symmetrical and anti-symmetrical vibrations of the $\mathrm{COO}^{-}$group, respectively

${ }^{\mathrm{d}} \mathrm{V}_{(\mathrm{C}=\mathrm{O})}$ : stretching frequency of the dimmer structure.

Table 2. Analytical data for the $\mathrm{M}(\mathrm{L})_{2} \cdot \mathrm{H}_{2} \mathrm{O}$ and $\mathrm{ML}_{2} \cdot \mathrm{nHL}$ compounds.

\begin{tabular}{|c|c|c|c|c|c|c|c|c|}
\hline \multirow{2}{*}{ Compound } & \multicolumn{3}{|c|}{ Metal oxide (\%) } & \multicolumn{2}{|c|}{$\Delta \mathrm{L}(\%)$} & \multicolumn{2}{|c|}{ HL or Water $(\%)$} & \multirow{2}{*}{ Residue } \\
\hline & Calcd. & TG & EDTA & Calcd. & TG & Calcd. & TG & \\
\hline $\mathrm{Mn}(\mathrm{L})_{2} \cdot 0.19 \mathrm{HL}$ & 19.75 & 19.57 & 19.88 & 72.76 & 72.92 & 7.49 & 7.46 & $\mathrm{Mn}_{3} \mathrm{O}_{4}$ \\
\hline $\mathrm{Co}(\mathrm{L})_{2} \cdot 0.28 \mathrm{HL}$ & 18.55 & 18.24 & 18.31 & 70.90 & 71.16 & 10.55 & 10.61 & $\mathrm{CoO}$ \\
\hline $\mathrm{Ni}(\mathrm{L})_{2} \cdot 0.13 \mathrm{HL}$ & 19.62 & 19.31 & 19.43 & 75.19 & 75.42 & 5.19 & 5.27 & $\mathrm{NiO}$ \\
\hline $\mathrm{Cu}(\mathrm{L})_{2} \cdot \mathrm{H}_{2} \mathrm{O}$ & 18.64 & 19.04 & 18.28 & 76.67 & 76.35 & 4.69 & 4.61 & $\mathrm{CuO}$ \\
\hline $\mathrm{Zn}(\mathrm{L})_{2} \cdot 0.081 \mathrm{HL}$ & 21.41 & 21.20 & 21.83 & 75.35 & 75.59 & 3.24 & 3.21 & $\mathrm{ZnO}$ \\
\hline
\end{tabular}

$\Delta \mathrm{L}=$ Ligand lost $\mathrm{HL}=3$-metoxibenzoic acid.

$\mathrm{M}=$ metal 
Nickel Compound. The TG-DTA and DSC curves are shown in Fig.2c. The mass loss that occurs between 50 and $200^{\circ} \mathrm{C}$ through slow process, without appearing of thermal event in the DTA and DSC curves, is due to the loss of 0.13 HL (3-methoxybenzoic acid) (Calcd. $=5.19 \%$; $\mathrm{TG}=5.27 \%$ ). Above this temperature up to $470^{\circ} \mathrm{C}$, the thermal decomposition occurs through a fast process, corresponding to the exothermic peak at $470^{\circ} \mathrm{C}$ (DTA, DSC) attributed to the oxidation of the organic matter. The profiles of the TG and DTA curves show that this step the oxidation of the organic matter is followed by combustion. The total mass loss up to $470^{\circ} \mathrm{C}$ is in agreement with the formation of $\mathrm{NiO}$, as final residue (Calcd. $=80.29 \%$; $\mathrm{TG}=$ $80.69 \%$ ) and confirmed by X-ray powder diffractometry.
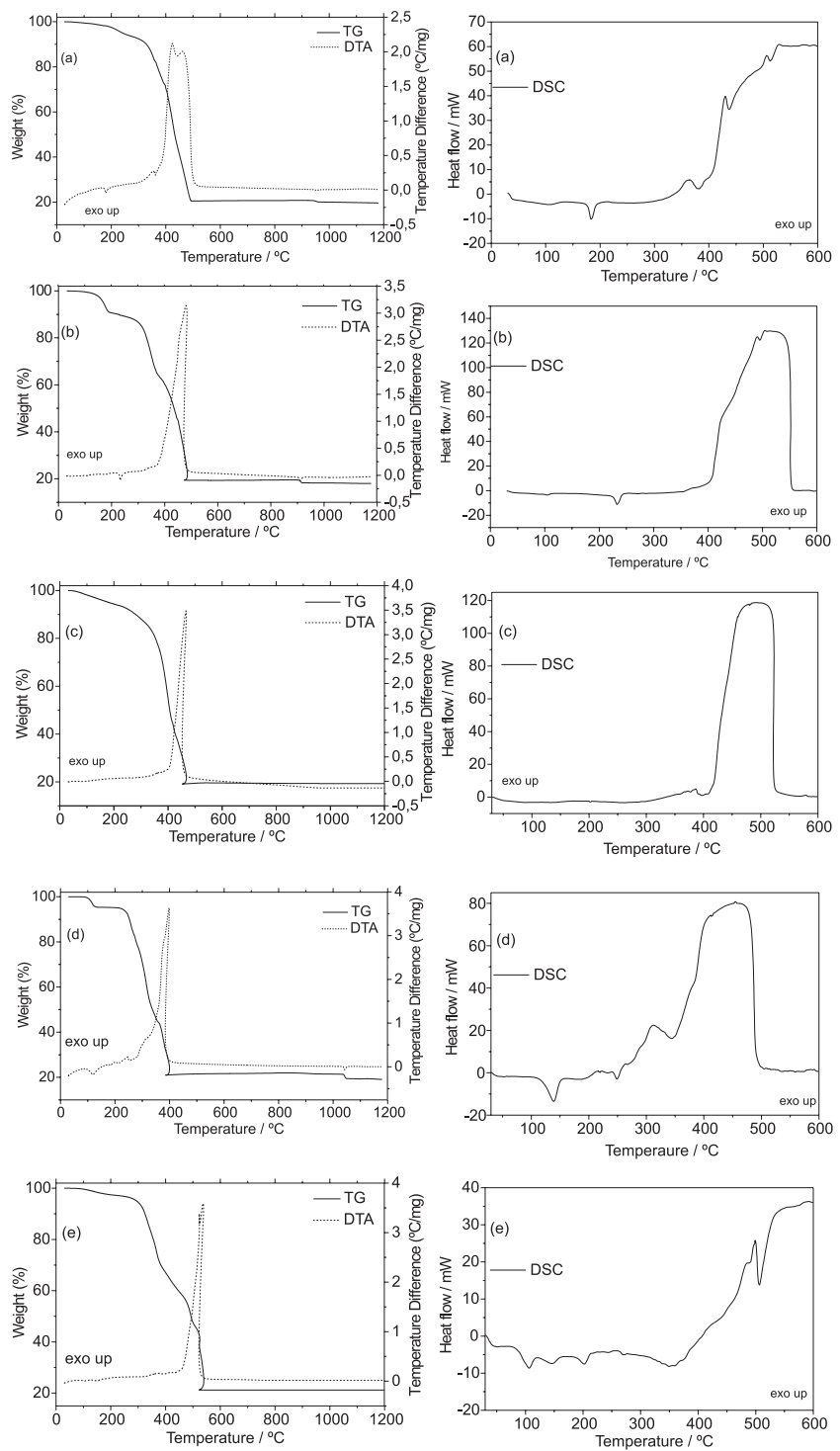

Figure 2. TG-DTA and DSC curves of the compounds: (a) $\mathrm{Mn}(\mathrm{L})_{2} .0 .19 \mathrm{HL}(\mathrm{m}=6.9788 \mathrm{mg})$, (b) $\mathrm{Co}(\mathrm{L})_{2} \cdot 0.28 \mathrm{HL}(\mathrm{m}=7.0760 \mathrm{mg}),(\mathrm{c}) \mathrm{Ni}(\mathrm{L})_{2} \cdot 0.13 \mathrm{HL}(\mathrm{m}=7.1162 \mathrm{mg}),(\mathrm{d}) \mathrm{Cu}(\mathrm{L})_{2} \cdot \mathrm{H}_{2} \mathrm{O}(\mathrm{m}=7.2794 \mathrm{mg})$ and (e) $\mathrm{Zn}(\mathrm{L})_{2} .0 .081 \mathrm{HL}(\mathrm{m}=7.1821 \mathrm{mg})$. L=3-methoxybenzoate, $\mathrm{HL}=3$-methoxybenzoate. 
Copper compound. The TG-DTA and DSC curves are show in Fig.2d. The mass loss observed between 95 and $130^{\circ} \mathrm{C}$, corresponding to an endothermic peak at $120^{\circ} \mathrm{C}$ (DTA), $140^{\circ} \mathrm{C}$ (DSC) is due to dehydration with loss of $1 \mathrm{H}_{2} \mathrm{O}$ (Calcd. = $4.69 \% ; \mathrm{TG}=4.61 \%$ ). The anhydrous compound is stable up to $210^{\circ} \mathrm{C}$, and above this temperature the thermal decomposition occurs in two consecutive steps with losses of $48.22 \%\left(210-355^{\circ} \mathrm{C}\right)$ and 26.13 $\%\left(355-400^{\circ} \mathrm{C}\right)$. These mass losses corresponding to the sharp exothermic peak at $400^{\circ} \mathrm{C}$ (DTA) or two exothermics between $290-340^{\circ} \mathrm{C}$ and $360^{\circ} \mathrm{C}$ (DSC), are attributed to the oxidation followed by combustion of the organic matter. The total mass loss up to $400^{\circ} \mathrm{C}$ is in agreement with the formation of $\mathrm{CuO}$ as the final residue (Calcd. $=79.28 \%$; $\mathrm{TG}=$ $78.96 \%$ ), which was confirmed by X-ray powder diffractometry. The last mass loss between 1034 and $1050^{\circ} \mathrm{C}$ corresponding to the endothermic peak at $1045^{\circ} \mathrm{C}$ is attributed to reduction of $\mathrm{CuO}$ to $\mathrm{Cu}_{2} \mathrm{O}$ (Calcd. $=2.08 \%$; $\mathrm{TG}=2.0 \%)$.

Zinc compound. The TG-DTA and DSC curves are shown in Fig. 2e. The mass loss observed between 90 and $240^{\circ} \mathrm{C}$ without appearing of thermal event in the DTA curve is due to the loss of $0.081 \mathrm{HL}$ (3-methoxybenzoic acid) Calcd. 3.24\%; TG $=3.21 \%$ ). In this temperature range the DSC curve shows three endothermic peaks at $110^{\circ} \mathrm{C}, 150^{\circ} \mathrm{C}$ and $200^{\circ} \mathrm{C}$, ascribed to sublimation of 3-methoxybenzoic acid, fusion and evaporation respectively. Above $240^{\circ} \mathrm{C}$, the thermal decomposition occurs in three steps with losses of $29.93 \%\left(240-380^{\circ} \mathrm{C}\right), 23.64 \%\left(380-500^{\circ}\right)$ and $26.02 \%$ (500-538\%), corresponding to the exothermic peaks at 520 and $538^{\circ} \mathrm{C}(\mathrm{DTA})$ and $500^{\circ} \mathrm{C}$ and exothermic between $540-600^{\circ} \mathrm{C}$ (DSC) attributed to oxidation of organic matter. The profiles of the TG and DTA curves show that the last step the oxidation of the organic matter is accompanied by combustion. The total mass loss up to $538^{\circ} \mathrm{C}$ is in agreement with the formation of $\mathrm{ZnO}$ as final residue $($ Calcd. $=78.59 \% ; \mathrm{TG}=78.80 \%)$ and confirmed by X-ray powder diffractometry.

The differences observed concerning the peak temperatures obtained by DTA and DSC, or peaks observed only in the DSC curves are undoubtedly due to the perforated cover used to obtain the DSC curves while the DTA ones are obtained without cover and due to the greater sensibility of the DSC.

\section{Conclusions}

The TG-DTA curves, infrared spectra and chemical analysis, permitted to verify that the binary compounds were obtained, however contaminated with 3-methoxybenzoic acid, except the copper compound. The procedure used to synthesize these compounds permitted to verify that compound little soluble (copper one) was obtained without contamination, and that the contamination occurs during the evaporation of the compounds solutions, due to the aggregation phenomenon.

The TG-DTA, also permitted verify that the $3-\mathrm{MeO}-\mathrm{HBz}$ is eliminated before thermal decomposition of these compounds, thus binary compounds may be obtained by thermosynthesis.

The X-ray powder patterns pointed out that the synthesized compounds have a crystalline structure, except the nickel one, without evidence concerning the formation of isomorphous series.

The infrared spectroscopy data suggest that the compounds considered in this work have an ionic character.

The TG-DTA and DSC provided previously unreported information about the thermal stability and thermal decomposition of these compounds.

\section{Acknowledgements}

The authors thank FAPESP (Proc. 97/126468), CNPq and CAPES foundations (Brazil) for financial support.

Recebido em: 18/03/2005

Aceito em: 29/04/2005 
A. C. Vallejo, A. B. Siqueira, E. C. Rodrigues, E.Y. Ionashiro, G. Bannach, M. Ionashiro

Síntese, caracterização e estudo térmico dos 3-metoxibenzoatos de alguns metais de transição, no estado sólido.

Resumo: Compostos M-3-MeO-Bz foram sintetizados no estado sólido, onde M representa os íons bivalentes $\mathrm{Mn}, \mathrm{Co}, \mathrm{Ni}, \mathrm{Cu}$ e Zn e 3-MeO-Bz o ânion 3-metoxibenzoato. Esses compostos foram caracterizados e estudados utilizando-se as técnicas de difração de raios x pelo método do pó, espectroscopia de absorção na região do infravermelho, análise química, termogravimetria e análise térmica diferencial simultânea (TG-DTA) e calorimetria exploratória diferencial (DSC). Os resultados forneceram informações com respeito à composição, desidratação, estabilidade térmica e decomposição térmica dos compostos isolados.

Palavras-chave: metais de transição bivalentes; 3-metoxibenzoato; comportamento térmico.

\section{References}

[1] S. J. Yun, S. K. Kang, S. S. Yun, Thermochim. Acta 331 (1999) 13.

[2] Z. M. Wang, L. J. van de Burgt, G. R. Choppin, Inorg. Chim. Acta 293 (1999) 167.

[3] N. Arnaud, J. Georges, Analyst 125 (2000) 1487.

[4] G. R. Choppin, P. A. Bertrand, Y. Hasegawa, N. Rizalla, Inorg. Chem. 21 (1982) 3722

[5] A. W. H. Lam, W. T. Wang, S. Gao, G. Wen, X. X. Zhang, Eu. J. Inorg. Chem. (2003) 149.

[6] W. W. Wendlandt. Anal. Chem. 17 (1957) 295.

[7] W. W. Wendlandt, Anal. Chem. 29 (1957) 800.

[8] T. Glowiak, H. Kozlowski, L. Strinna Erre, B. Gulinati, G. Micera, A. Pozzi, S. Brunni, J. Coord. Chem. 25 (1992) 75.

[9] W. Brzyska and S. Karasinski, J. Thermal Anal. 39 (1993) 429.
[10] W. Ferenc and A. Walkow-Dziewulska, J. Thermal Anal. Cal. 71 (2003) 375.

[11] H. A. Flaschka, EDTA Titrations, Pergamon Press, Oxford, 1964.

[12] C. N. de Oliveira, M. Ionashiro, C. A. F. Graner, Ecl. Quim. 10 (1985) 7.

[13] G. Socrates, Infrared Characteristic Group Frequencies, 2nd ed., Wiley, New York, 1994, pp.91 and 236-237.

[14] R. M. Silverstein, F. X. Webster, Spectrometric Identification of Organic Compounds 6th ed., Wiley, New York, 1998, pp. 92, 93, 96 and 97.

[15] I. A. Petroni, F. L. Fertonani, C. B. Melios, M. Ionashiro Thermochim. Acta 400 (2003) 187.

[16] Z. P. Xu, H. C. Zeng, J. Mater. Chem. 89 (1998) 2499. 